\title{
Bolu-Yedigöller Yaban Hayatı Geliştirme Sahası'nda saf meșe meşceresinde fotokapanla tespit edilen memeli türler
}

\author{
Mustafa NABİOĞLU*, Yrd. Doç. Dr. Akif KETEN² \\ ${ }^{1}$ Bolu Orman Bölge Müdürlüğü, Bolu Orman İşletme Müdürlüğü, BOLU \\ ${ }^{2}$ Düzce Üniversitesi, Orman Fakültesi, Yaban Hayatı Ekolojisi ve Yönetimi Bölümü, DÜZCE \\ *Sorumlu yazar/Corresponding author: umit_naiboglu061@hotmail.com, Geliş tarihi/Received: 08.03.2016, Kabul tarihi/Accepted: 11.04.2016 \\ $\ddot{\mathbf{O} z}$ \\ Son yıllarda meşe ormanlarının öneminin artması bu habitatların daha fazla araştırılma gereksinimini ortaya çı- \\ karmıştır. Bu çalışma Bolu-Yedigöller Yaban Hayatı Geliştirme Sahası'ndaki bir saf meşe meşceresindeki memeli \\ türlerin belirlenmesi amacıyla yapılmıştır. Yaklaşık bir yıl boyunca (Eylül 2013-Temmuz 2014) sabit noktalardan \\ fotokapanlarla gözlemler yapılmıştır. Tespit edilen 10 memeli türe ait 1415 görüntüde 2231 yaban hayvanı bireyi \\ sayılmıştır. Yaban domuzu, karaca ve kızıl tilki alandaki en baskın türlerdir. Meşcerede yaban hayvanları mevsimsel \\ farklılık göstermemektedir. Daha çok beslenme davranışı görülmüştür. Türler genel olarak gececildir. Yaban hayatı \\ bakımından zengin olan meşe meşcerelerinde sürdürülebilir yönetimin devam ettirilmesi önerilmektedir.
}

Anahtar Kelimeler: Yaban hayatı, saf meșe, fotokapan, memeli türler.

\section{Mammals determined by wildlife camera trap in pure oak stand in Bolu-Yedigöller Wildlife Reserve}

\begin{abstract}
In recent years, increasing importance of the oak forests has revealed the requirement for further investigation of these habitats. The current study was conducted to determine the species of mammals in a pure oak stand in BoluYedigöller Wildlife Reserve. The observations were made by wildlife camera traps from fixed-points for about a year, from September 2013 to July 2014. A total of 10 species of mammals was identified, and 2231 individuals were counted from 1415 wild animal images. Wild boar, roe deer and red fox are the most dominant species in the area. Wild animals do not show seasonal variations in the stands. Feeding behavior was observed more than the other activities. The species is nocturnal in general. We suggest continuing the sustainable management in oak stands that are rich in terms of wildlife
\end{abstract}

Keywords: Wildlife, pure oak, camera trap, mammals.

To cite this article (Atıf): Nabioğlu, M., Keten, A., 2016. Bolu-Yedigöller Yaban Hayatı Geliştirme Sahası'nda saf meşe meșceresinde fotokapanla tespit edilen memeli türler. Orman Genel Müdürlüğü Ormancılık Araştırma Dergisi 1(3):62-68 DOI: 10.17568/oad.22425

\section{Giriş}

Türkiye gerek tür zenginliği, gerekse kapladığ 1 alan bakımından dünyanın sayılı meşe diyarlarından biridir. Meşe ormanları hem toprak muhafaza, hem odun hammaddesi, hem de biyolojik çeşitlilik unsuru olarak hizmet eden değerli bir ekosistemimizdir (Yaltırık, 1984). Bununla birlikte, tüm dünya meşe ormanlarında, özellikle Amerika'da ve Avrupa'da sebebi tam olarak ortaya konmamış meşe ölümleri gözlenmektedir (Makineci ve ark., 2011). Bu nedenle meşe ormanları ormancılığın her disiplini tarafından araştırılmalıdır.

Ormanlar yaban hayvanlarına besin ve barınak olmaktadır. Özellikle besin değeri yüksek meşe palamutları sonbahar ve kış aylarında yaban hayvanları tarafından tüketilmektedir (McShea ve Schwede, 1993). Sadece meşe palamutları ile beslenme nega- tif azot dengesizliği yapsa da hayvanlar palamutlara ek olarak diğer besinleri de tüketerek protein ihtiyaçlarını gidermektedir (Kirkpatrick ve Pekins, 2002). Diğer taraftan, yaban hayvanları toprak özelliklerini ve orman altı florayı etkiler (Mohr ve ark., 2005). Yine, memeliler kuşlarla birlikte meşe türlerinin yayılmasında ve yenilenmesinde faydalı olmaktadir (Mellanby, 1968).

Dünya genelinde meşe ormanları ile yaban hayatı ilişkisini ortaya koyan pek çok araştırma yapılmıştır (Twedt ve Wilson, 2002; Schroeder ve Vangilder, 1997; Harlow ve ark., 1975; Rodewald ve Smith,1998; Dickson, 2004; Morrison ve ark., 1991; Aigner ve ark., 1998, vb.). Ülkemizde ise saf meşe ormanlarında yapılan sınırlı sayıda (Makineci ve ark., 2011) çalışma bulunmaktadır. Bazı çalışmalar ise genel örnekleme arasında meşe orman- 


\section{Bolu-Yedigöller Yaban Hayatı Geliştirme Sahası'nda saf meşe meşceresinde fotokapanla tespit edilen memeli türler}

larını da kapsamaktadır (Beşkardeş, 2009; Can ve Togan, 2009).

Son yıllarda karasal memeli türler ile ilgili arazi çalışmalarında fotokapanlar yaygın olarak kullanılmakta ve diğer metodlar kadar kullanışlı olduğu belirtilmektedir (Roberts, 2011). Hatta diğer metodlara göre ekonomiklik ve veri elde edilişi bakımından diğer metodlardan daha avantajlı olmaktadır (Silveira ve ark., 2003). Bu yöntemlerle özellikle iri cüsseli memeli türlerin popülasyon tahmini yapılmaya çalışılmaktadır (Rowcliffe ve ark., 2008). Bu çalışma, fotokapanlar ile Bolu ilinde bulunan ve önemli yaban hayatı alanlarından birisi olan Yedigöller Yaban Hayatı Geliştirme Sahas1 (YHGS)'nda bir saf meşe meşceresindeki yaban hayvanı türlerinin belirlenmesi için yapılmıştır.

\section{Materyal ve Yöntem}

\subsection{Calışma alanı}

Çalışma alanı; Batı Karadeniz Bölgesinde BoluMerkez İlçe Sınırları içerisinde olup kuzeyinde Yığılca, güneyinde Bolu, doğusunda Mengen, batısında Düzce yerleşim merkezleri bulunmaktadır (Şekil 1). İdari bakımdan ise Bolu Orman Bölge Müdürlüğü, Bolu Orman İşletme Müdürlüğü, Sar1çam Orman İşletme Şefliğine bağlıdır. Çalışmanın yapıldığg ve büyüklüğü 70 ha olan ormanın meş-

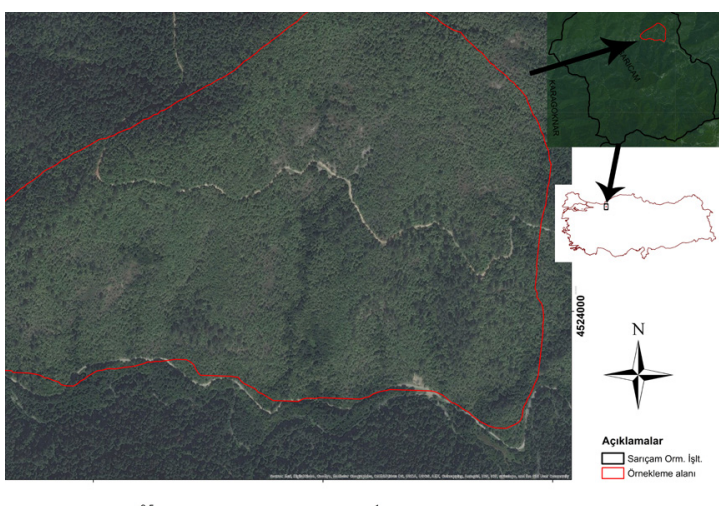

Şekil 1. Çalışmanın yapıldığı Sarıçam Orman İşletme Sefliği 28 nolu bölme

Figure 1. The location of the study area, unit 28 in Sarıçam Forest Management Planning Unit

cere tipi Mc3’tür. Alan, aynı zamanda Yedigöller Yaban Hayatı Geliştirme Sahası (YHGS) içerisinde ve sahanın güneybatısında kalmaktadır.

Çalışma alanı, ortalama \%80 eğime sahip olup, hakim bakısı güneydir. Ortalama yüksekliği $1.000 \mathrm{~m}$ olan sahaya en yakın su kaynağı, güneyinden geçen Kara Dere'dir. Çalışma alanı içerisindeki ve etraftaki diğer bütün sulu ve kuru dereler bu dere ile birleşmektedir. Saha yazları serin, kışları oldukça sert geçen Karadeniz ardı iklim karakterine sahiptir. Meşcerenin doğusu, batısı ve kuzeyinde meşe ağırlıklı ormanlar; güneyinde ise göknar ve kayın ormanları mevcuttur. Alanda meşenin dişında yer yer göknar, kayın, çam, gürgen, titrek kavak, kiraz gibi ağaç türleri bulunmaktadır. Alt tabakada ise ağaççık ve çalı formunda; orman sarmaşı̆̆ 1 , orman gülü, böğürtlen, laden, kızılcık, muşmula, alıç, kuşburnu, ahlat, çoban püskülü, taflan, defne, tespih ağacı, ayı üzümü gibi türler, otsu bitki formunda ise; sıklamen, eğrelti, kardelen, orman çileği, adaçayı, nane, papatya, çiğdem, sütleğen, yüksük otu, kekik, güzelavratotu, yonca ve çayır otları türleri yer almaktadır.

\subsection{Veri toplama}

Çalışma sahasına 21 Eylül 2013 ile 3 Ağustos 2014 tarihleri arasinda 8 noktaya en az 300 m mesafe ile fotokapan kurulmuştur (Şekil 2). Fotokapanlar arasındaki mesafe alanı temsil edebilecek şekilde dizayn edilmiştir. Örnekleme noktalarının

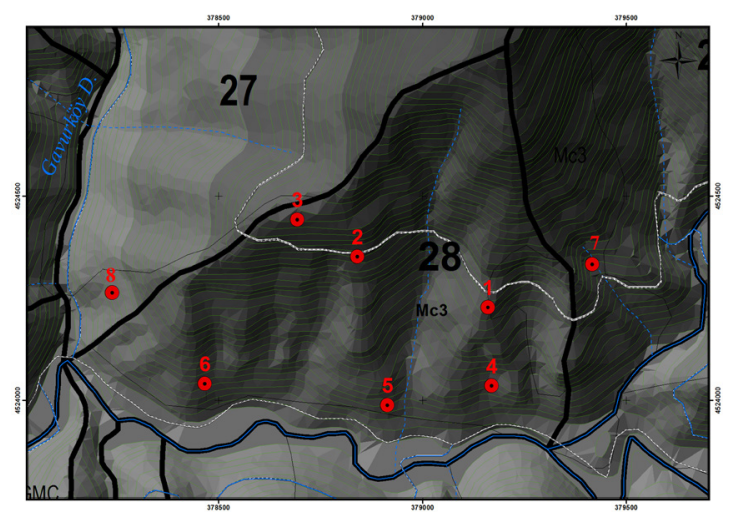

Şekil 2. Fotokapan kurulan örnekleme noktaları.

Figure 2. The sampling plots where camera traps are set.

koordinatları, eğim, bakı, yükselti, meşcere ağaç türleri, ağaç sayısı, kapalılık, ortalama çap, ortalama boy ve diri örtü oranı Tablo 1'de verilmiştir.

Fotokapanlar yaban hayvanlarının muhtemel yaşam alanlarına ve/veya geçiş güzergahlarına kurulmuştur. Arazi çalışması süresince aylık periyotlarla fotokapanlar kontrol edilerek görüntüleri bilgisayara aktarılmıştır. Öncelikle canlı tespit edilen fotoğraflar ayrılmış, canlı tespit edilemeyen fotoğraflar silinmiştir. Canlı tespiti yapılan fotoğraflar hayvan türlerine göre ayrılmıştır. Tür tespitleri Macdonald ve Barrett (1993) ve Aunagnier ve ark. (2009)'na göre yapılmıştır. Fotoğraflar üzerindeki tarih ve saat bilgileri tür bazında not edilmiştir. Birey sayıları tespit edilirken ya tek 


\section{Mammals determined by wildlife camera trap in pure oak stand in Bolu- Yedigöller Wildlife Reserve}

fotoğraftaki en fazla sayı, ya da sürü halinde dolaşan hayvanların geçişlerine göre elde edilen toplam sayı kullanılmıştır. Yine, fotokapanın art arda çekim yapmasından dolayı zaman bilgisi ve birey sayıları elde edilirken aynı bireylere ait olduğu kanısına varılan fotoğraflardan sadece birisi kullanılmıştır. Hayvanların davranışları (beslenme, geçiş vb.) fotokapanlardan yararlanılarak not edilmiștir.

Tablo 1. Örnekleme noktalarının koordinatları ve habitat özellikleri

Table 1. The geographic positions and habitat features of the sampling plots

\begin{tabular}{|c|c|c|c|c|c|c|c|c|c|c|c|}
\hline \multirow{2}{*}{ 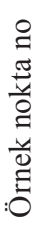 } & \multicolumn{2}{|c|}{ Koordinat } & \multirow{2}{*}{$\begin{array}{l}\Xi \\
\text { 活 } \\
\text { I }\end{array}$} & \multirow{2}{*}{$\frac{\bar{y}}{\tilde{\varpi}}$} & \multirow{2}{*}{ 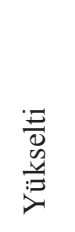 } & \multirow{2}{*}{ 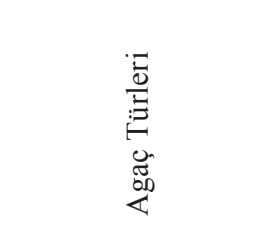 } & \multirow{2}{*}{ 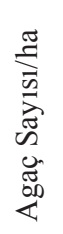 } & \multirow{2}{*}{ 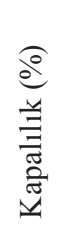 } & \multirow{2}{*}{ 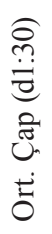 } & \multirow{2}{*}{ 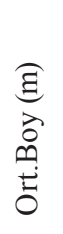 } & \multirow{2}{*}{ 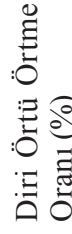 } \\
\hline & $\mathrm{D}(\mathrm{X})$ & $\mathrm{K}(\mathrm{Y})$ & & & & & & & & & \\
\hline 1 & 379160 & 4524228 & 55 & G & 952 & M,G,Çs,Çk & 425 & 75 & 22 & 15 & 70 \\
\hline 2 & 378840 & 4524352 & 90 & G & 998 & M & 495 & 100 & 24 & 15 & 85 \\
\hline 3 & 378605 & 4524435 & 55 & G & 1051 & $\mathrm{M}, \mathrm{G}, \mathrm{Kn}, \mathrm{C} \mathrm{s}$ & 580 & 95 & 22 & 13 & 60 \\
\hline 4 & 379161 & 4523993 & 90 & G & 820 & M Kn, ,Gn,Krz,Fn & 241 & 90 & 35 & 20 & 10 \\
\hline 5 & 378916 & 4523935 & 45 & G & 799 & $\mathrm{M}, \mathrm{Kn}, \mathrm{G}, \mathrm{Gn}$ & 283 & 95 & 35 & 18 & 10 \\
\hline 6 & 378463 & 4523998 & 85 & G & 800 & $\mathrm{M}, \mathrm{G}, \mathrm{C} s, \mathrm{Kn}$ & 807 & 85 & 22 & 12 & 80 \\
\hline 7 & 379430 & 4524315 & 100 & GD & 746 & $\mathrm{M}, \mathrm{Kn}, \mathrm{G}, \mathrm{Ak}, \mathrm{Krz}$ & 382 & 90 & 22 & 12 & 80 \\
\hline 8 & 378175 & 4524200 & 100 & GB & 773 & $\mathrm{M}, \mathrm{Kn}, \mathrm{G}, \mathrm{Gn}$ & 368 & 90 & 26 & 20 & 20 \\
\hline
\end{tabular}

(D (X): Doğu boylamı; K (Y):Kuzey enlemi; M: Meşe; Kn: Kayın; G: Göknar; Ak: Akçaağaç; Krz: Yabani kiraz; Gn: Gürgen; Çs: Sarıçam; Çk: Karaçam; Fn: Fındık) (D: Longitude; K: Latitude; M: Oak; Kn: Beech; G: Fir; Ak: Acer; Krz: Wild cherry; Gn: Hornbeam; Çs: Scots pine; Çk: Black pine; Fn: Hazelnut)

Fotoğraf üzerinde bulunan zamanlar not edilmiştir. Çalışma sırasında Şekil 2'deki 4 nolu fotokapan çalınmış olup 22.04.2014-06.07.2014 tarihleri arasında görüntü alınamamıştır. Çalınan fotokapanın yerine tekrar kapan kurulmuştur.

\subsection{Veri analizi}

Örneklemede aylık gün sayılarının farklılığı ve kaybolan fotokapandan dolayı fotokapan çalışma süreleri eşit olmadığından 100 günlük sabit süre

Tablo 2. Tespit edilen türlerin görüntülenme değerleri ve alanı kullanış şekilleri Table 2. The number of views and usage patterns of identified species

\begin{tabular}{|c|c|c|c|c|c|c|c|c|}
\hline Takım & Familya & Türler & 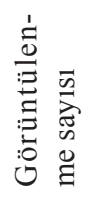 & 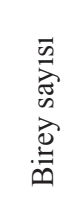 & 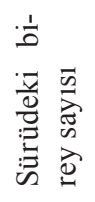 & 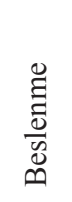 & 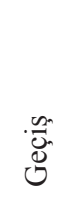 & 㐫 \\
\hline Rodentia & Sciuridae & Sciurus anomalus (Anadolu sincabı) & 41 & 43 & 1.05 & 37 & 3 & 1 \\
\hline Carnivora & Canidae & Canis lupus (Kurt) & 42 & 53 & 1.26 & 0 & 42 & 0 \\
\hline Carnivora & Canidae & Vulpes vulpes (K1z1l tilki) & 275 & 281 & 1.02 & 63 & 211 & 1 \\
\hline Carnivora & Ursidae & Ursus arctos (Bozay1) & 71 & 132 & 1.86 & 26 & 45 & 0 \\
\hline Carnivora & Mustelidae & Martes foina (Kaya sansar1) & 24 & 24 & 1.00 & 7 & 16 & 1 \\
\hline Carnivora & Mustelidae & Meles meles (Porsuk) & 9 & 9 & 1.00 & 2 & 7 & 0 \\
\hline Carnivora & Felidae & Felis sylvestris (Yaban kedisi) & 33 & 33 & 1.00 & 3 & 30 & 0 \\
\hline Artiodactyla & Suidae & Sus scrofa (Yaban domuzu) & 468 & 1168 & 2.50 & 364 & 104 & 0 \\
\hline Artiodactyla & Cervidae & Capreolus capreolus (Karaca) & 412 & 442 & 1.07 & 336 & 72 & 4 \\
\hline Artiodactyla & Cervidae & Cervus elaphus (Kizıl geyik) & 19 & 25 & 1.32 & 5 & 14 & 0 \\
\hline Carnivora & & Tanımsız & 8 & 8 & 1.00 & & & \\
\hline Diğer & & & 13 & 13 & 1.00 & & & \\
\hline & & TOPLAM & 1415 & 2231 & & 843 & 544 & 7 \\
\hline
\end{tabular}




\section{Bolu-Yedigöller Yaban Hayatı Geliştirme Sahası'nda saf meşe meşceresinde fotokapanla tespit edilen memeli türler}

için veriler dönüştürülmüştür. Bunun için; $100 \mathrm{x}$ Görüntü sayısı / Fotokapan gün sayısı formülü uygulanmıştır (Kinnaird ve O'brien, 2012). Memeli türlerinin aylara göre dağılımları bu değere göre yapılmıştır. Gün içerisindeki aktif olduğu zamanlar ve davranış özellikleri görüntülenme sayısına göre düzenlenmiştir. Sayısal olarak baskınlığı \%10'un üzerinde olan türlerin ayrı ayrı zamansal dağılımları değerlendirilmiştir. Tanımlanamayan türler değerlendirmeye alınmamış, sadece miktarlarıyla belirtilmiştir. Görüntülenme sayılarına göre zamansal farklılığın test edilmesi için varyans analizi (ANOVA) yapılmıştır. Cinsiyeti belirgin olan
Cervidae familyasına ait türlerin cinsiyet oranları ortaya konulmuştur. Fotokapan görüntülerinden, türün görüldüğü saatler belirlenerek aktif olduğu zaman aralıkları ve davranışları not edilerek alan kullanım şekilleri ortaya konulmuştur. Analizlerin tümü Program R kullanılarak yapılmıştır (R Development Core Team, 2015)

\section{Bulgular}

Çalışmada toplam 2447 fotokapan günü gözlem yapılmıştır. Elde edilen 20.000'i aşkın fotoğraftan 10 memeli türüne ait toplam 1.415 görüntüde 2.231 yaban hayvanı bireyi sayılmıştır (Tablo 2).

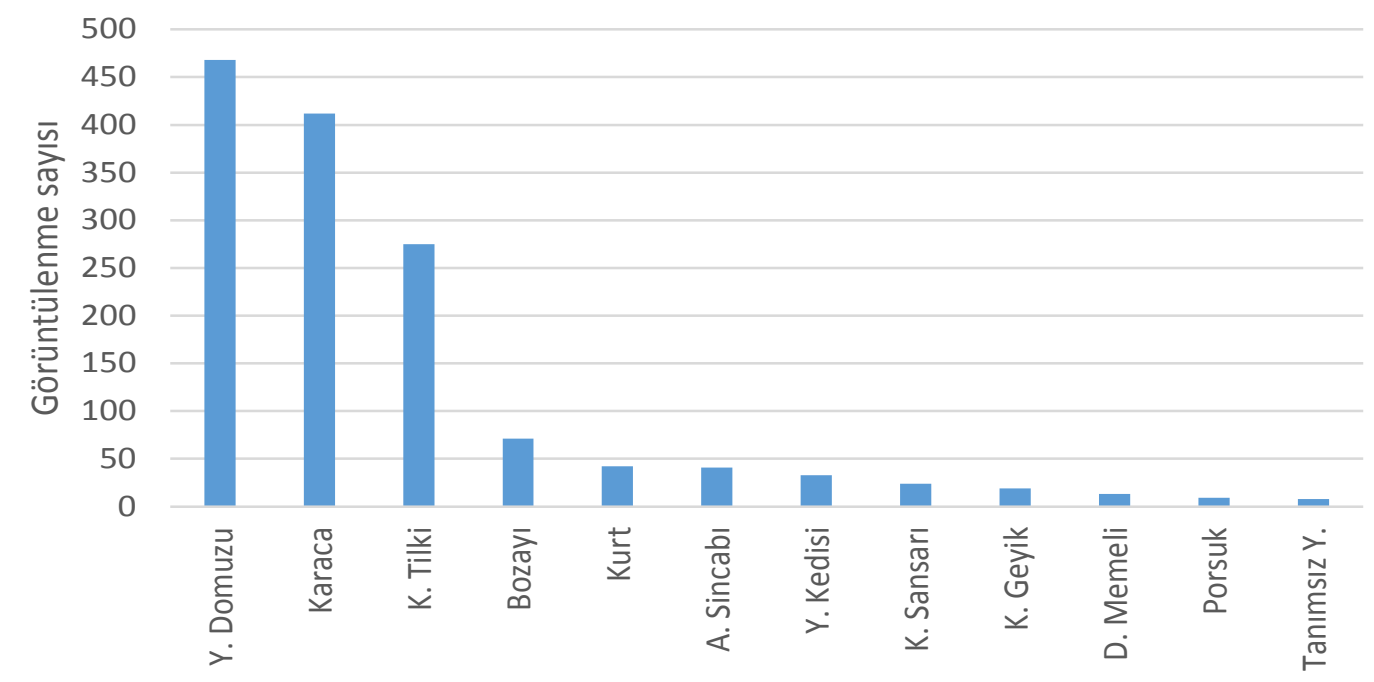

Tür

Şekil 3. Türlerin görüntülenme sayılarının bolluk sıralaması

Figure 3. The rankings of the species according to the number of views

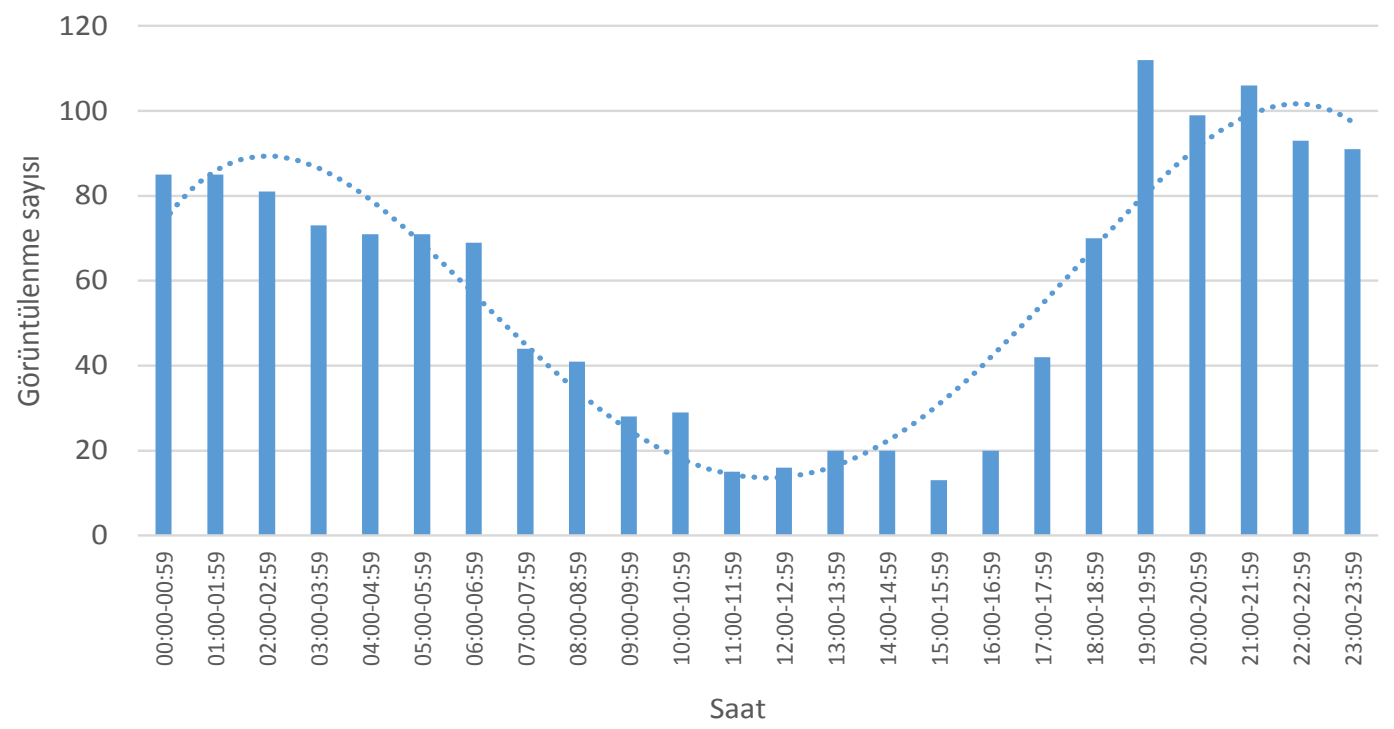

Şekil 4. Tespit edilen tüm yaban hayvanı türlerine ait görüntü sayılarının gün içerisindeki zamansal dağılımı Figure 4. Temporal distribution of views of the wild animals captured by trap cameras 


\section{Mammals determined by wildlife camera trap in pure oak stand in Bolu- Yedigöller Wildlife Reserve}

Bunlardan 8 kez tanımlanamayan yırtıcı, 13 kez de diğer memeli (kirpi, fare vb.) türü birer birey ile fotoğraflanmıştır. Genel görüntülenme oranı 100 fotokapan günü için $57,8^{\prime}$ dir. Toplam görüntülenmenin \%82'sini oluşturan ve baskınlık oranı yüksek olan 3 tür sirasiyla Yaban domuzu, Karaca ve K1zıl tilkidir (Şekil 3). Yaban domuzunun sürüdeki ortalama birey sayısı 2,5 iken Bozayı, Kızıl geyik ve Kurt dışındaki türler çoğunlukla bireysel tespit edilmiştir.

Türler çoğunlukla beslenme davranışı (\%60) göstermiştir. Ergin olarak sayılan ve cinsiyeti belirli olan 442 Karacanın cinsiyet oran 1 1:0,75 ve birey sayısı 23 olan K1zıl geyiğin cinsiyet oranı ise

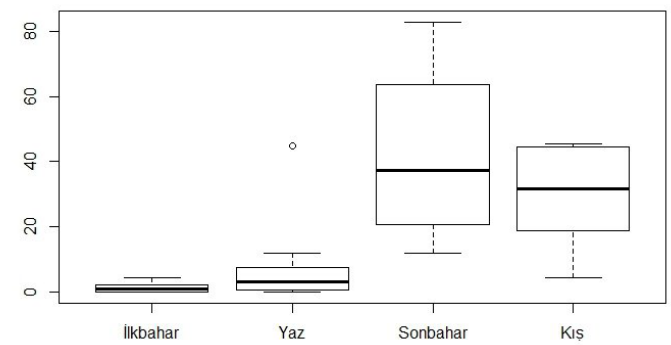

(a) 1:0,28'dir. Günün her saatinde aktif olan türler çoğunlukla gececil olup en fazla akşam saatlerinde görüntülenmiştir (Şekil 4). Yaban hayvanlarının görüntülenme oranı mevsimsel olarak farklılık göstermemektedir $\left(\mathrm{F}_{3 ; 28}=1,849 ; \mathrm{P}=0,161\right)$.

Baskınlık oranı yüksek olan türlerden Yaban domuzu çalışmanın yapıldığı periyot içerisinde sonbahar ve kış aylarında daha yüksek oranda gözlenmiştir. Bu durum mevsimsel olarak anlamlı farklılık oluşturmuştur $\left(\mathrm{F}_{3: 28}=9,744 ; \mathrm{P}<0,001\right)$. Diğer baskın tür Karaca da mevsimsel olarak değişiklik göstermektedir $\left(\mathrm{F}_{3: 28}=2,971 ; \mathrm{P}=0,0487\right)$ (Şekil 5a). Karaca alanı daha çok bahar ve yaz aylarında kullanmaktadır. Baskın türlerden Kızıl tilki

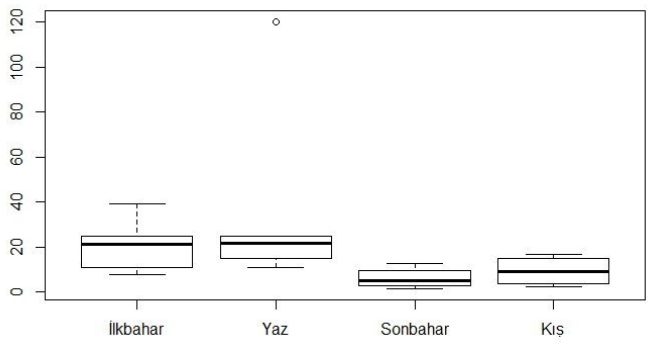

(b)

Şekil 5. Yaban domuzunun (a) ve karacanın (b) mevsimsel farklılıkları Figure 5. The seasonal differences of wild boar and roe deer

ise mevsimsel olarak farklılık göstermemektedir $\left(\mathrm{F}_{3: 28}=1,436 ; \mathrm{P}=0,253\right)$. Yaban domuzu ve K1z1l tilki çoğunlukla gece faaliyet gösterirken, Karacanın zaman zaman yüksek oranda gündüz aktivitesi bulunmaktadır (Şekil 5b).

\section{Tartışma ve Sonuç}

Bolu Yedigöller YHGS içerisinde bulunan meşe ormanında yaban hayvanlarının alanı kullanım oranı oldukça yüksektir. Bunda alanın ve yakın çevresinin yaban hayatı için uygun olması ve sahanın yaban hayvanlarının geliştirilmesi için koruma statüsünün bulunması etkili olmuştur. Saha, yerleşim yerlerinden ve yoğun insan etkisinden uzaktır. Ancak hem orman içi yolların kullanımı, hem de orman işletmeciliği nedeniyle yaban hayvanları yaşam alanlarında insan faaliyetleri bulunmaktadir.

Birçok yaban hayvanı insan aktivitesinin olduğu alanlarda çoğunlukla gececil davranmaktadır (George ve Crooks, 2006).

Yedigöller YHGS içerisinde ve yakın bölgesinde daha önce belirlenen (Beşkardeş 2009) türlerden Çakal, Vaşak ve Yaban tavşanı hariç tümü bu çalışma kapsamında gözlenebilmiştir. En sık gözlenen türler sırasıyla Yaban domuzu, Karaca, Kızıl tilki ve Bozayı'dır. Beşkardeş (2009) ise en fazla sırasıyla Yaban domuzu, Karaca, Kızıl geyik ve Bozayı'yı tespit etmiştir.

Sahanın saf meşe meşceresi olması baskın türlerin sıralamasını etkilemiştir. En önemli besin kaynağ1 kemirgenler olan Kizıl tilkinin (Lanszki ve ark., 2007) çalışma alanında YHGS genelinden daha fazla görülmesi besin kaynağının meşe ormanlarında daha fazla olmasından (Dueser ve Shugart, 1978; Makineci ve ark., 2011) kaynaklandığı düşünülebilir. Beşkardeş (2012), Yedigöller YHGS'nda kızıl geyiğin karacaya göre populasyon yoğunluğunun düşük olduğunu bildirmiştir. Çalışma alanında kızıl geyik oldukça az tespit edilebilmiştir.

Yaban domuzu, bozayı ve kızıl geyik genel olarak grup davranışı göstermektedir.

Yaban hayvanı türleri özellikle de otçullar alanı en çok beslenme amaçlı kullanmaktadır. Bunda Artiodactyla türlerinin daha çok meşe altı flora ile beslenmesinin etkisi görülmektedir (Sheremet'ev ve Prokopenko, 2006). Çalışmanın yapıldığı Mc3 meşceresi hem otçul, hem de etçil türler için iyi bir beslenme alanını oluşturmaktadır. Baskın türlerden Karacanın ilkbahar ve yaz aylarında daha yoğun görülmesi beslenme davranışından kaynaklanmaktadır. Yaban domuzu, hayvansal gidanın 


\section{Bolu-Yedigöller Yaban Hayatı Geliştirme Sahası'nda saf meşe meşceresinde fotokapanla tespit edilen memeli türler}

yanı sıra enerji değeri yüksek olan kestane, meşe palamutu ve kayın fıstığ 1 gibi besinleri tüketmektedir. Beslenme davranıșı uzamsal ve zamansal farklılık göstermektedir (Schley ve Roper, 2003). Türün alanda sonbahar ve kış aylarında daha yüksek bulunması meşe palamutlarını tüketmesinden kaynaklanmaktadır. Geçiş habitatı olarak kullanımın yanı sıra zaman zaman türler alanı dinlenme amaçlı da kullanmaktadır.

Doğal eşey oranı 1:1 değerine yakın olan Kızıl geyik ve Karacanın erkek/dişi oranı sapmalar göstermektedir. Cinsiyet oranında belirgin faktörler olmamakla birlikte çevresel etkiler öne çıkmaktadır. Düşük popülasyon yoğunluğunda baskın dişiler daha çok erkek birey doğurmaktadır. Bunda beslenme stresi ve kış şartları etkili olmaktadır (Kruuk ve ark., 1999). Dişi Karacaların vücut ağırlığ1nın düşük olması erkek birey yavrulama oranını artırmaktadır (Hewison ve Gaillard, 1996). Diğer taraftan erkek Cervidae bireyleri dişiye göre daha geniş yaşam alanına sahiptir (Lamberti ve ark., 2006). Sonuçta erkek bireylerin daha geniş alanlarda dolaşması fotokapanlarda daha yüksek oranda yakalanmasına neden olmuş olabilir.

Ülkemiz av hayvanları arasında potansiyeli yüksek olan türlerin Meşe ormanlarında yoğun olarak bulunması önemli bir sonuçtur. Özellikle küçük ölçekli bir alanda çok sayıdaki iri cüsseli memeli türünün aynı habitatı kullanması biyolojik zenginliğin bir göstergesidir. Bu zenginliğin devamı için mevcut alanların tahrip edilmeden ve sürdürülebilir şekilde yönetilmesi faydalı olacaktır.

Not: Bu çalışma Düzce Üniversitesi Fen Bilimleri Enstitüsü’nde "Saf Meşe Ormanlarında Bakım Müdahalesinin Yaban Hayatına Kısa Dönemdeki Etkisi" adlı Yüksek Lisans Tez çalışmasından alınmıştır.

\section{Kaynaklar}

Aigner, P.A., Block, W.M., Morrison, M.L., 1998. Effect of firewood harvesting on birds in a California oak-pine woodland. The Journal of wildlife management 62 (2): 485-496.

Aulagnier, S., Mitchell-Jnes, A.J., Moutou, F., Zima, J, Haffner, P., 2009. Mammals of Europe, North Africa and the Middle East. ISBN-10:1408113996, A\&C Black Publishers Ltd., $272 \mathrm{~s}$.

Beşkardeş, V., 2012. Yedigöller ve Yeşilöz Yaban Hayatı Geliştirme Sahaları avifaunası üzerine araştırmalar. Turkish Journal of Forestry Türkiye Ormancllk Dergisi 13(1): 28-34.

Beşkardeş, V., 2009. Yedigöller Yaban Hayatı Koruma ve Geliştirme Sahasında Yaban Hayatı Yönetimi. İ.Ü. Fen Bilimleri Enstitüsü, Doktora Tezi, İstanbul, $162 \mathrm{~s}$.

Can, Ö. E., Togan, İ., 2009. Camera trapping of large mammals in Yenice Forest, Turkey: local information versus camera traps. Oryx 43(3): 427-430.

Dickson, J.G., 2004. Wildlife and upland oak forests. Gen. Tech. Rep. SRS-73. Asheville, NC: U.S. Department of Agriculture, Forest Service, Southern Research Station. pp. 106-115.

Dueser, R.D., Shugart Jr, H.H., 1978. Microhabitats in a forest-floor small mammal fauna. Ecology 59(1): 89-98.

George, S.L., Crooks, K.R., 2006. Recreation and large mammal activity in an urban nature reserve. Biological Conservation 133(1): 107-117.

Harlow, R.F., Whelan, J.B., Crawford, H.S., Skeen, J.E., 1975. Deer foods during years of oak mast abundance and scarcity. The Journal of Wildlife Management 39(2): 330-336.

Hewison, A.M., Gaillard, J.M., 1996. Birth-sex ratios and local resource competition in roe deer, Capreolus capreolus. Behavioral Ecology 7(4): 461-464.

Kinnaird, M.F., O'brien, T.G., 2012. Effects of PrivateLand Use, Livestock Management, and Human Tolerance on Diversity, Distribution, and Abundance of Large African Mammals. Conservation Biology 26(6): 10261039.

Kirkpatrick, R.L., Pekins, P.J., 2002. Nutritional value of acorns for wildlife. Oak Forest Ecosystems. The Johns Hopkins University Press, Baltimore, 173-181.

Kruuk, L.E., Clutton-Brock, T.H., Albon, S.D., Pemberton, J.M., Guinness, F.E., 1999. Population density affects sex ratio variation in red deer. Nature 399(6735): 459-461.

Lanszki, J., Zalewski, A., Horváth, G., 2007. Comparison of red fox Vulpes vulpes and pine marten Martes martes food habits in a deciduous forest in Hungary. Wildlife Biology 13(3): 258-271.

Lamberti, P., Mauri, L., Merli, E., Dusi, S., Apollonio, M., 2006. Use of space and habitat selection by roe deer Capreolus capreolus in a Mediterranean coastal area: how does woods landscape affect home range?. Journal of Ethology 24(2): 181-188.

Makineci E., Yilmaz E., Özdemir E., Kumbasli M., Sevgi O., Keten A., Beşkardeș V., Zengin H., Yılmaz H., Çalışkan S., 2011. Kuzey Trakya koruya tahvil mese ekosistemlerinde saglik durumu, biyokütle, karbon depolama ve faunistik özelliklerin belirlenmesi TÜBITAK Projesi, TUBITAK-TOVAG 107O750, Turkiye.

Macdonald, D.W., ve Barrett, P., 1993. Mammals of Britain \& Europe. HarperCollins.

McShea, W.J., Schwede, G., 1993. Variable acorn crops: responses of white-tailed deer and other mast consu- 


\section{Mammals determined by wildlife camera trap in pure oak stand in Bolu- Yedigöller Wildlife Reserve}

mers. Journal of Mammalogy 74(4): 999-1006.

Mellanby, K., 1968. The effects of some mammals and birds on regeneration of oak. Journal of applied Ecology 5(2): 359-366.

Mohr, D., Cohnstaedt, L.W., Topp, W., 2005. Wild boar and red deer affect soil nutrients and soil biota in steep oak stands of the Eifel. Soil Biology and Biochemistry 37(4): 693-700.

Morrison, M.L., Block, W.M., Verner, J., 1991. Wildlife-Habitat Relationships in California's Oak Woodlands: Where Do We Go from Here?. In: Standiford, Richard B., tech. coord. 1991. Proceedings of the symposium on oak woodlands and hardwood rangeland management; October 31 - November 2, 1990; Davis, California. Gen. Tech. Rep. PSW-GTR-126. Berkeley, CA: Pacific Southwest Research Station, Forest Service, U.S. Department of Agriculture; p. 105-109.

R Development Core Team, 2015. R: A Language and Environment for Statistical Computing. R Foundation for Statistical Computing Vienna, Austria.

Rowcliffe, J.M., Field, J., Turvey, S.T., Carbone, C., 2008. Estimating animal density using camera traps without the need for individual recognition. Journal of Applied Ecology, 45 (4): 1228-1236.

Roberts, N.J., 2011. Investigation into survey techniques of large mammals: surveyor competence and camera-trapping vs. transect-sampling. Bioscience Horizons 4(1): 40-49.
Rodewald, P.G., Smith, K.G., 1998. Short-term effects of understory and overstory management on breeding birds in Arkansas oak-hickory forests. The Journal of wildlife management 62(4): 1411-1417.

Schley, L., Roper, T.J., 2003. Diet of wild boar Sus scro$f a$ in Western Europe, with particular reference to consumption of agricultural crops. Mammal review 33(1): 43-56.

Schroeder, R.L., Vangilder, L.D., 1997. Tests of wildlife habitat models to evaluate oak-mast production. Wildlife Society Bulletin 25(3): 639-646.

Sheremet'ev, I.S., Prokopenko, S.V., 2006. General analysis of forest vegetation in the south of the Far East with regard to the feeding of wild ruminants (Artiodactyla, Ruminantia). Russian Journal of Ecology 37(4): 217-224.

Silveira, L., Jacomo, A.T., Diniz-Filho, J.A.F., 2003. Camera trap, line transect census and track surveys: a comparative evaluation. Biological Conservation, 114(3): 351-355.

Twedt, D. J., Wilson, R.R., 2002. Development of oak plantations established for wildlife. Forest Ecology and Management 162(2): 287-298.

Yaltırık, F., 1984. Türkiye Meşeleri Teşhis Kılavuzu. Tarım, Orman ve Köyişleri Bakanlığ 1 , Orman Genel Müdürlüğü Yayınları, Yenilik Basımevi, İstanbul, Pp: 64. 